\title{
Um Teatro para os Universitários de São Paulo e Além
}

\section{A Theater for University of São Paulo Students and Beyond}

\section{RESUMO}

Este artigo trata das atividades desenvolvidas no Teatro da Universidade de São Paulo (TUSP) com relação à formação em artes cênicas e ao teatro amador e vocacional. Inicia-se com um breve resgate histórico do TUSP, evidenciando sua importância para a constituição do campo teatral e a modernização do teatro brasileiro. Em seguida, são apresentadas suas principais atividades para o público vocacional e amador, para a formação de público, para os alunos de artes cênicas e para a reflexão e crítica sobre o campo teatral. Reflete sobre a importância do teatro universitário no tensionamento e crítica das práticas teatrais vigentes.

Palavras-chave: Teatro da USP (TUSP). Teatro universitário. Teatro brasileiro.

\section{ABSTRACT}

This article is about the activities of University of São Paulo Theater (TUSP) related to the amateur and vocational theater as well as the formation in Stage Arts. It reveals its importance to the theater field and the modernization of Brazilian Theater. Besides, its main activities are shown: the ones related to vocational and amateur theater; the public formation and theater pedagogy, to Stage Arts students; and to the reflection and critics of the theater field. It also considers the importance of the university theater in tensioning and criticizing the theatrical practices.

Keywords: USP Theater (TUSP). Academical theater. Brazilian theater. 
No campo teatral, não há consenso, nem definição usual e corrente, de "teatro universitário". Ao contrário, as tentativas de conceituação esbarram em limitações institucionais e teóricas, confundindo o teatro universitário com o teatro amador, o vocacional, o estudantil ou o de pesquisa e experimental. É nesse sentido que a Enciclopédia Itaú Cultural de Teatro o define:

Entende-se por teatro universitário não propriamente uma categoria teatral mas, sobretudo, um olhar inovador e menos convencional sobre a cena. Confunde-se, algumas vezes, com o teatro amador e com o teatro estudantil, nos seus sentidos amplos, fronteiras nem sempre nítidas entre essas manifestações que, todavia, apresentam um traço em comum: a recusa dos padrões convencionais da expressão teatral. [2]

Há registros de atividade teatral ligada ao meio estudantil no Brasil desde o século XIX, com notável presença nessa época da Faculdade de Direito do Largo São Francisco. Na primeira metade do século XX, as principais manifestações de teatro universitário ocorreram no Rio de Janeiro, sobretudo por iniciativa de Paschoal Carlos Magno, que em 1938 criou o Teatro do Estudante do Brasil, o TEB. Nas décadas seguintes, Carlos Magno promoveu festivais de teatro universitário em várias cidades do país, ajudando a alavancar e difundir o moderno teatro brasileiro, modernização iniciada com a renovação da cena - cuja montagem de Vestido de Noiva, de Nelson Rodrigues, pela companhia carioca Os Comediantes é um dos marcos - e pela profissionalização das companhias, iniciada em São Paulo com o Teatro Brasileiro de Comédias (sobre a modernização do teatro brasileiro, ver [1]).

No bojo desse processo de modernização foi criado o Teatro da USP.

\section{HISTÓRIA}

A primeira iniciativa de criação de um teatro da Universidade de São Paulo data de 1955, quando a reitoria atendeu a uma solicitação dos diretórios acadêmicos, que por sua vez seguiam diretrizes do XVI Congresso da União Nacional dos Estudantes (UNE) realizado em 1953. Essa primeira fase, que duraria somente dois anos, teve como diretor o ator Ruy Affonso Machado, então membro do elenco do TBC (para uma história mais minuciosa do Teatro da USP, ver [3]).

Na efervescência dos anos 1960, o TUSP reaparece entre 1966 e 1968, por iniciativa dos alunos da Faculdade de Filosofia, Ciências e Letras (hoje Faculdade de Filosofia, Letras e Ciências Humanas - FFLCH) e da Faculdade de Arquitetura e Urbanismo (FAU). Esse teatro ganhou o nome de Teatro dos Universitários de São Paulo e, apesar de ter surgido na USP, não mantinha vínculos formais com a Universidade. Registrou, porém, atividades que envolviam alunos e professores. Em 1967 ocorreu um dos pontos altos desse período, a montagem de Os Fuzis da Senhora Carrar, de Bertold Brecht, com direção de Flávio Império. Esse trabalho viajou por vários estados brasileiros e participou, em 1969, do Festival de Teatro Universitário de Nancy, na França. Com o agravamento da situação política no país, sobretudo após a decretação do Ato Institucional 
Número Cinco (AI-5), o Teatro dos Universitários de São Paulo se dissolveu.

Oito anos depois, já na débâcle do regime militar, o reitor Orlando Marques de Paiva assina a resolução 943, de 26 de maio de 1976, que recriou o Teatro da USP e o vinculou à então Coordenadoria de Atividades Culturais (CODAC). O primeiro diretor dessa fase foi Décio de Almeida Prado, professor da USP, crítico e historiador do teatro brasileiro. Sem sede própria, as atividades passaram a ser feitas no auditório da Biblioteca Municipal Anne Frank, na rua Cojuba, 45, no bairro do Itaim Bibi, cedido à USP pelo prazo de vinte anos, de 1976 a 1996. Miroel Silveira, também crítico e professor de teatro na USP, sucedeu Prado na direção do teatro. A partir de 1986, o TUSP passou a ser responsabilidade da Escola de Comunicações e Artes (ECA) e a receber os espetáculos curriculares do Departamento de Artes Cênicas (CAC) e da Escola de Arte Dramática (EAD).

Foi, porém, com o fim da CODAC, em 1990, que o TUSP passou a ganhar as feições que tem hoje. Subordinado a então recém-criada Pró-Reitoria de Cultura e Extensão Universitária, passou a ser um polo gerador de cultura. Seu primeiro diretor nessa fase foi Abílio Tavares, egresso do curso de Artes Cênicas da USP. Foi nesse período que se iniciaram ações nos campi da USP no interior, sobretudo por meio de festivais itinerantes de teatro universitário. Em 1996, sua sede foi transferida para o prédio da rua Maria Antônia, no centro da cidade de São Paulo.

Em 2006, sob a direção do ator, diretor e professor da EAD Celso Frateschi, o TUSP ampliou seus programas e passou a buscar uma aproximação maior com o meio discente. As diretrizes instituídas por Frateschi*, atualmente em sua segunda gestão no órgão, visam um diálogo maior entre as muitas manifestações teatrais realizadas na universidade, não somente as relacionadas à formação em artes cênicas. Além disso, cabe à universidade tensionar o campo teatral como um todo, valorizando as dimensões crítica e vanguardista atreladas à sua constituição.

\section{PORTAS ABERTAS}

O regimento do TUSP estabelece como seus objetivos, entre outros, "estimular a criação e o desenvolvimento de grupos teatrais universitários em todos os campi da Universidade de São Paulo, da capital e do interior, propiciando, através destes, amplo acesso ao fazer teatral e à integração entre a comunidade interna" e "promover o intercâmbio teatral com universidades e demais instituições teatrais do Brasil e do exterior".

Nesse sentido, a atual gestão do TUSP compreende que o teatro deve estar aberto a quaisquer manifestações teatrais realizadas por estudantes de qualquer área, não somente ligadas às artes cênicas. Dessa forma, algumas atividades específicas visam integrar grupos de teatro amadores e vocacionais* da USP e de outras universidades, em especial as localizadas no estado de São Paulo.

\section{$A(P)$ arte e $A(P)$ arte da Vez}

Em 1967 e 1968, estudantes ligados ao Teatro da USP lançaram a revista $a(P)$ arte, cuja continuidade naquele período foi inviabilizada dada a conjuntura política do momento.
*Maria Thais, professora da ECA/USP e premiada diretora teatral dirigiu o TUSP entre a primeira e a segunda gestão de Frateschi, época em que ganhou fôlego o Circuito TUSP.

*Assim como não há um consenso sobre o conceito de "teatro universitário", não existe uma definição única para "teatro amador" ou "vocacional". Aqui, essas duas expressões ("amador" e "vocacional") referem-se ao teatro realizado não com 
objetivos profissionais, mas sim como desejo, seguindo as reflexões do diretor alemão Manfred Wekwerth.
Em 2010, o TUSP relançou a revista, agora chamada $a(P)$ arte XXI. A revista é, atualmente, composta das seguintes seções:

" Os "aPartes", artigos curtos, sobre temas específicos, em diálogo com outros artigos; os "aPartes" são feitos, principalmente, por estudantes e profissionais que se oferecem para escrever a partir de um tema dado;

" As “Tentativas para Debate”, seção dedicada à (re)publicação de textos incendiários e que fomentam a discussão teatral;

" A publicação de peças inéditas e outros tipos de artigo, como artigos fotográficos ou contribuições de leitores e dos envolvidos nas atividades do TUSP;

" Além disso, a cada número, o TUSP convida artistas que tenham relação com as artes cênicas ou com a universidade, a fim de ilustrar a revista e dialogar com os temas propostos.

No lançamento do terceiro número, em dezembro de 2010, realizou-se uma assembleia de arte, idealizada por Celso Frateschi e pelos orientadores de artes dramáticas do TUSP. Por meio de um chamamento público, vários coletivos universitários se inscreveram para, em cinco minutos, apresentarem seus trabalhos. Valia de tudo: leitura de poesia, música, cenas de teatro e dança, performances, improvisações. Após uma primeira rodada, os grupos iniciavam um diálogo entre si, mas que só permitia que fossem utilizadas linguagens artísticas.

Essa experiência, que era para ser única, somente no lançamento da revista, tornou-se uma atividade permanente e autônoma, demandada pelos participantes e que, a cada edição, incorpora novos coletivos. Constituiu-se em um espaço ao mesmo tempo lúdico e criativo, no qual se integram estudantes e outras pessoas ligadas às universidades e escolas de formação. Mais ainda, estimula a vitalidade da produção artística e aproxima concepções estéticas e críticas diversas, contribuindo para a pluralidade e a diversidade tão caras à vida universitária.

\section{Jornada de Teatro Universitário}

Duas edições da Jornada de Teatro Universitário, realizadas em dezembro de 2011 e setembro de 2012, reuniram universitários em uma experiência sui generis. Cada jornada durou três dias e começava com a apresentação de uma cena curta de cada um dos grupos participantes. No dia seguinte, os grupos misturavam-se e, sob a orientação de diretores profissionais, criavam novas cenas, apresentadas à noite. $\mathrm{O}$ último dia era um espaço de reflexão sobre o fazer teatral. Participam da jornada estudantes da capital e do interior, sendo que a última edição contou também com dois grupos de fora do estado de São Paulo (um do Rio Grande do Sul, outro do Ceará), que solicitaram participar dada a repercussão positiva da primeira edição. Para os alunos de fora da cidade de São Paulo, o TUSP, com recursos da Pró-Reitoria de Cultura e Extensão Universitária, oferece hospedagem, transporte e alimentação.

Para o TUSP, a jornada é um momento importante, pois passamos a conhecer melhor quem de fato produz teatro nas universidades hoje. Mais ainda, a produção da jornada consiste em um ensaio para a realização de outras atividades, como a Bienal de Teatro que se planeja para o ano de 2013. 


\section{FORMAÇÃO DE PÚBLICO}

Também está previsto no regimento do TUSP "divulgar as artes cênicas nas suas mais diferentes manifestações e formas de expressão" e "promover a realização de cursos, palestras, debates e festivais, divulgando a cultura teatral junto à comunidade em geral”. Tais objetivos visam, sobretudo, a formação de público, constituindo-se, portanto, em um espaço de pedagogia do teatro, de arte-educação, de sensibilização para as práticas teatrais e, sobretudo, para o desenvolvimento do senso estético e do gosto pelas atividades culturais para a comunidade que está além dos muros da USP.

\section{Leituras Públicas}

O Programa TUSP de Leituras Públicas propõe o dizer de peças de eminentes autores do teatro ocidental. As peças são lidas pelo público presente, pela área artístico-pedagógica do TUSP, por artistas em formação e por atores convidados. Este programa faz parte dos Núcleos de Experiência e Apreciação Teatral do TUSP, que tem mediação dos orientadores de arte dramática do órgão. Espera-se, por meio dele, criar um público que vá além da presença eventual e que acompanhe cada ciclo, abrindo espaço para uma experiência diferenciada de plateia que fortaleça o sentido de pertencimento à coisa pública por meio da experiência estética.

A escolha das peças que formam cada ciclo está ligada às questões que o TUSP trabalha naquele momento específico, relacionando-se com outras atividades e debates correntes. Por exemplo, o número quatro da revista $a(P)$ arte tratou da questão do cômico e o ciclo equivalente na época teve como tema "Leituras da Comédia Brasileira". Quando o TUSP voltou-se para o debate sobre a Comissão da Verdade e o resgate da memória política, realizou-se o ciclo “Teatro, Verdade e Justiça”.

\section{Circuito TUSP}

O Circuito TUSP de Teatro é um programa de ação continuada para a difusão das artes cênicas nos campi da Universidade de São Paulo, em parceria com outros espaços públicos no interior do estado, como os Teatros Municipais e Seções de Atividades Culturais. Pretende oferecer formas diversificadas de convívio com a experiência cênica, cultivando o hábito da fruição teatral entre a comunidade universitária e o público externo.

A fim de ampliar a representatividade da produção teatral desenvolvida no âmbito universitário, o Circuito TUSP de Teatro tem incluído em sua programação não apenas espetáculos realizados no Departamento de Artes Cênicas da ECA/USP (CAC) e na Escola de Arte Dramática (EAD), mas também espetáculos de escolas convidadas e grupos profissionais. Além da apresentação das peças, há uma intensa programação de ações paralelas e outras atividades diversas, como workshops, trocas com grupos locais, ciclos de palestras, exibições de filmes e vídeos. $\mathrm{O}$ formato atual do circuito é realizado em cinco dias, com um grupo profissional abrindo o evento. 


\section{FUTUROS PROFISSIONAIS}

Ainda de acordo com o regimento do TUSP, cabe ao órgão

[...] desenvolver projetos em parceria com o Departamento de Artes Cênicas - CAC - e a Escola de Arte Dramática - EAD, ambos da Escola de Comunicações e Artes ECA/USP, e outras Unidades e Órgãos, com o objetivo de estabelecer pontos de intersecção entre os trabalhos e estudos desenvolvidos na Universidade nas áreas de ensino, pesquisa e extensão.

Assim, o TUSP abre espaço anualmente para o escoamento dos trabalhos oriundos das escolas de formação teatral, com vistas à profissionalização, não mais restringindo-se ao teatro amador e vocacional.

\section{Mostra Experimentos}

A Mostra Experimentos é uma ação continuada do TUSP cujo objetivo é oferecer uma pequena amostragem da produção das escolas de formação em teatro - em nível superior e/ou técnico - do estado de São Paulo. A cada edição da Mostra, são experimentados novos desdobramentos - tais como workshops, sessões comentadas de espetáculos e diálogos após as apresentações -, sem nunca perder de vista seu papel de divulgação da produção dessas escolas. Trata-se de uma atividade aguardada pelas escolas, pois se constitui em um momento propício e profícuo para a apresentação de trabalhos concluídos ou em processo.

A Mostra Experimentos tem por parceiros habituais o Departamento de Artes Cênicas (CAC) da ECA/USP, a Escola de Arte Dramática (EAD) da USP, a Unicamp, a Escola Livre de Teatro (ELT) de Santo André, a Fundação das Artes de São Caetano do Sul (FASCS) e a Unesp, mais recentemente recebendo também participações da SP Escola de Teatro, da Universidade São Judas Tadeu e da Escola Superior de Artes Célia Helena, entre outras.

\section{PROPOSIÇÕES}

Por fim, completam as atividades do TUSP conforme seu regimento: "pesquisar, produzir e montar espetáculos em programações definidas por convite, curadoria ou edital de seleção e aprovados pelo Conselho Deliberativo" e "promover realização de temporadas em seu espaço cênico, por meio de apresentações de companhias e grupos teatrais internos ou externos à Universidade de São Paulo, em programações definidas por convite, curadoria ou edital público".

Trata-se de ações únicas, definidas em função do debate que se instala no momento, seja no âmbito da universidade, seja no campo teatral. Foi assim, por exemplo, que o TUSP organizou, em julho de 2011, a mostra "Militância Teatral na Periferia”, com curadoria do pesquisador Sebastião Milaré, que deu voz a sete grupos que surgiram e se mantêm em atividade na periferia de São Paulo. Na mesma linha, o TUSP realizou em maio e junho de 2012 o ciclo "Jorge Andrade 90 anos: (re)leituras", que promoveu debates e leituras dramáticas sobre um dos mais importantes dramaturgos paulistas. Desse ciclo, 
resultaram também duas publicações, uma já lançada e outra em fase de elaboração.

Na mesma linha, o TUSP promoveu temporadas de grupos e companhia significativas para a cena contemporânea e que, de alguma maneira, dialogam com os objetivos do órgão. Por exemplo, entre outras ações, abrigou as comemorações dos dez anos da Cia. Livre de Teatro, dirigida pela professora do CAC Cibele Forjaz; realizou a mostra de repertório do Grupo 59, oriundo da EAD; abriu as portas para mostra da Escola Livre de Teatro, de Santo André, uma das mais tradicionais e importantes da cena contemporânea; realizou intensa programação sobre tragédias gregas por ocasião da ocupação da Cia. Balagan, capitaneada por Maria Thais, ex-diretora do TUSP e professora da ECA.

Por fim, por meio de editais lançados ao longo do ano, o TUSP recebeu companhias profissionais que trabalham com teatro experimental e de pesquisa, cujas peças foram selecionadas por uma comissão externa e independente. Com isso, responde a demandas da comunidade externa.

\section{NOVO SALTO}

Em reunião do Conselho de Cultura e Extensão da USP realizada em 9 de agosto de 2012, foi aprovada a criação da Bienal de Teatro da Universidade de São Paulo. O TUSP considera a realização dessa bienal um projeto de grande relevância, primeiramente, porque inexiste na cidade de São Paulo, um dos principais polos culturais no Brasil e no cenário internacional, qualquer iniciativa dessa envergadura na esfera pública. Também destacamos a propósito do conceito de Bienal, que para além de delimitar um período específico - o que certamente incrementa a avaliação de tendências artísticas contemporâneas -, possibilita o investimento em formas de ação cultural nos campos da teoria e da prática, que livres de convenções presentes em festivais de teatro, cujo enfoque, em muitos casos, projeta-se para o mercado, podem reputar-se ao estudo, ao aprofundamento crítico, à averiguação de outras modalidades e enfoques artísticos.

Portanto, por seu ineditismo no contexto de uma política pública para a cidade de São Paulo, e por sua expressiva capacidade em fazer convergir a excelência da pesquisa acadêmica da USP e intersecções com outros pesquisadores e instituições no Brasil e fora dele, somado ao que há de mais profícuo nas artes cênicas, também em âmbito nacional e internacional, acreditamos ser a bienal projeto de inequívoco potencial para a difusão da arte teatral em nossa atualidade, redimensionando a experiência artística e seus desdobramentos simbólicos e imateriais como forma de se pensar o mundo.

É um novo salto, maduro, que resgata atribuições da universidade perdidas ao longo do tempo, sobretudo após passarmos pelo período da ditadura militar, que restringiu e dilapidou as atividades artísticas. A bienal resgata, portanto, o papel interventor da universidade no campo artístico, prevendo:

" Apresentações de espetáculos de companhias e coletivos com histórico profissional, vocacional ou universitário, nacionais e/ou internacionais;

" Apresentações de materiais cênicos diversos: partilhas de processos de criação em forma de ensaios abertos, exposição de procedimentos ou treinamentos performativos; 
" Apresentações de materiais cênicos desenvolvidos a partir de estímulos ou provocações dentro do próprio evento;

"T Trocas estético-pedagógicas entre artistas, pesquisadores, coletivos, companhias ou produções artísticas participantes;

" Oficinas, workshops ou cursos de curta duração;

„Palestras, debates ou mesas de discussões em formatos diversos.

\section{CONCLUSÃO}

Este texto, ainda que aparentemente panfletário, busca mostrar para o público da Revista Cultura e Extensão USP as diretrizes e atividades do Teatro da USP, que acreditamos estar em consonância com as da Pró-Reitoria de Cultura e Extensão Universitária (PR$\mathrm{CEU}$ ). Dessa forma, o TUSP insere-se não apenas no âmbito da vivência universitária, mas também se relaciona com a sociedade que o abarca e insere-se no campo artístico e na história do teatro brasileiro.

\section{REFERÊNCIAS BIBLIOGRÁFICAS}

[1] ARRUDA, Maria Arminda do Nascimento. Metrópole e Cultura. São Paulo no Meio Século XX. Bauru: Edusc, 2001.

[2] ITAÚ CULTURAL. Teatro Universitário. Disponível em: http://www.itaucultural.org.br/aplicexternas/enciclopedia_teatro/index.cfm?fuseaction $=$ conceitos biografia\&cd_verbete $=619$. Acesso em: 3 set. 2012.

[3] TAVARES, Abílio César Neves. A USP e seu Teatro. Um Olhar Retrospectivo e Prospectivo. Dissertação de mestrado, São Paulo: ECA-USP, 2008.

[4] WERWERTH, Manfred. Diálogo sobre a Encenação: Um Manual de Direção Teatral. São Paulo: Hucitec, 1997.

\section{AGRADECIMENTOS}

Ainda que seja assinado, este artigo é resultado de reflexões e práticas diárias feitas pela equipe do TUSP: Celso Frateschi, Cláudia Alves Fabiano, Deise Abreu Pacheco, Dilson Rufino, Francisco Serpa Peres, René Marcelo Piazentin Amado, Otacílio Alacran, Magali Chamiso Chamellette de Oliveira, Fábio Larsson, Neuza Aparecida Moreira Cirqueira, Nilton Casagrande, Rogério Cândido dos Santos, Rodrigo Bari, Elcio Silva, Marcos Chichorro dos Santos, Vanessa Azevedo de Morais. As referências desse artigo à revista $a(P)$ arte XXI, às Leituras Públicas, ao Circuito TUSP e à Mostra Experimentos partiram de outros textos escritos coletivamente por essa equipe, tanto na atual gestão (dirigida por Celso Frateschi) quanto na anterior (dirigida por Maria Thais). 
FERDINANDO MARTINS professor doutor de Estética e História da Arte da Escola de Comunicações e Artes da Universidade de São Paulo (ECA-USP), vice-diretor do Teatro da USP (TUSP) e coordenador do Programa USP Diversidade, do Núcleo de Direitos da PRCEU. É pesquisador do Núcleo de Pesquisa em Comunicação e Censura da USP/Observatório de Liberdade de Expressão e Censura e-mail: ferdinando.martins@gmail.com 